\title{
Incidence of Tumour Progression and Pseudoprogression in High-Grade Gliomas: a Systematic Review and Meta-Analysis
}

\author{
Abdul W. Abbasi ${ }^{1}$ Henriette E. Westerlaan' ${ }^{*}$ Gea A. Holtman ${ }^{3}$ Kamal M. Aden $^{1}$ Peter Jan van Laar ${ }^{1,2}$ • \\ Anouk van der Hoorn',2 (D)
}

Received: 16 December 2016 / Accepted: 4 April 2017 / Published online: 2 May 2017

(C) The Author(s) 2017. This article is an open access publication.

\begin{abstract}
Background High-grade gliomas are the most common primary brain tumours. Pseudoprogression describes the false appearance of radiation-induced progression on MRI. A distinction should be made from true tumour progression to correctly plan treatment. However, there is wide variation of reported pseudoprogression. We thus aimed to establish the incidence of pseudoprogression and tumour progression in high-grade glioma patients with a systematic review and meta-analysis.

Methods We searched PubMed, Embase and Web of Science on the incidence of pseudoprogression and tumour progression in adult high-grade glioma patients from 2005 , the latest on 8 October 2014. Histology or imaging followup was used as reference standard. Extracted data included number of patients with worsening of imaging findings on T1 postcontrast or T2/FLAIR, pseudoprogression and tumour progression. Study quality was assessed. Heterogene-
\end{abstract}

Electronic supplementary material The online version of this article (doi: 10.1007/s00062-017-0584-x) contains supplementary material, which is available to authorized users. It contains the characteristics of the included studies (supplementary table 1) and a full search strategy (see supplementary search strategy).

Anouk van der Hoorn

a.van.der.hoorn@umcg.nl

1 University Medical Center Groningen, Department of Radiology, University of Groningen, Hanzeplein 1, 30.001, 9700 RB Groningen, The Netherlands

2 University Medical Center Groningen, Center for Medical Imaging-North East Netherlands, University of Groningen, Groningen, The Netherlands

3 University Medical Center Groningen, Department of General Practice, University of Groningen, Groningen, The Netherlands ity was tested with $I^{2}$. Pooling of the results was done with random models using Metaprop in STATA (StataCorp. Stata Statistical Software. College Station, TX: StataCorp LP).

Results We identified 73 studies. MRI progression occurred in 2603 patients. Of these, 36\% (95\% confidence interval [CI] 33-40\%) demonstrated pseudoprogression, $60 \%$ (95\%CI 56-64\%) tumour progression and unknown outcome was present in the remaining $4 \%$ of the patients (range $1-37 \%)$.

Conclusion This meta-analysis demonstrated for the first time a notably high pooled incidence of pseudoprogression in patients with a form of progression across the available literature. This highlighted the full extent of the problem of the currently conventional MRI-based Response Assessment in Neuro-Oncology (RANO) criteria for treatment evaluation in high-grade gliomas. This underscores the need for more accurate treatment evaluation using advanced imaging to improve diagnostic accuracy and therapeutic approach.

Keywords Treatment response assessment · Metaanalysis · Pseudoprogression · Incidence · High-grade gliomas

\section{Introduction}

Glioblastoma multiforme (GBM) is the deadliest brain cancer, often fatal within a year after diagnosis [1]. This poor prognosis is mainly due to the inevitability of recurrent disease. Imaging is important for accurate treatment evaluation of patients with a glioblastoma. T1-weighted MRI with gadolinium combined with T2/FLAIR is currently the standard imaging technique [2]. However, postcontrast T1 only reflects biological activity of the tumour indirectly, by 
detecting the breakdown of the blood-brain barrier [3]. T1weighted MRI does not directly measure tumour size or tumour activity and is non-specific.

Recurrent disease appears as a new contrast-enhancing lesion on T1-weighted MRI or growth of the high T2/ FLAIR area. However, a similar presentation may result from treatment effects resulting in the false appearance of disease progression, i.e., pseudoprogression [3-5]. Thus, in the case of progression on imaging, it is necessary to distinguish true tumour progression from pseudoprogression to correctly tailor treatment.

Although recognised as a clinically important problem, there exists a wide variation in the reported incidence of pseudoprogression. Previous studies individually indicating its incidence vary in the range of $3 \%$ to over $50 \%[3,6]$. One of the major limitations of these studies was their small sample sizes. The high variance in the reported incidence of pseudoprogression impedes subsequent treatment decisions.

In order to clarify how often progression occurs, the current meta-analysis systematically reviewed the studies that recorded incidences of pseudoprogression and tumour progression in high-grade glioma patients.

\section{Methods}

\section{Search Strategy}

A systematic review and meta-analysis was performed according to the meta-analysis of observational studies in epidemiology (MOOSE) criteria [7], the preferred reporting items for systematic reviews and meta-analyses (PRISMA) criteria [8], and the assessing the methodological quality of systematic reviews (AMSTAR) guidelines [9].

We systematically searched MEDLINE (PubMed), Embase and Web of Science. Database keywords and text words were used aiming at patients with a high-grade glioma and tumour progression or pseudoprogression, with synonyms for each (see "Appendix" for search strategy). We used both treatment-induced pseudoprogression and radionecrosis in our search strategy, as they belong to a spectrum of radiation-induced injury. We searched the databases from 2005, the time at which temozolomide was included in the standard treatment, till 8 October 2014. No other filters or restrictions were applied. Non-English studies were manually excluded later. Conference proceedings are included in Embase and this thus allowed for the inclusion of grey literature in the meta-analysis. Study selection and data extraction was completed by two authors independently (AA and KA). In the case of inconsistencies, a third author was consulted (AH or HW).

\section{Selection Criteria}

Inclusion criteria were studies having a consecutive or random selection of adult patients diagnosed with a high-grade glioma following standard care of treatment with first-line concomitant chemoradiotherapy with temozolomide, followed by adjuvant temozolomide. Surgical resection was not mandatory for inclusion, as some patients did not receive surgical resection due to contraindications, such as comorbidity. Histological confirmation, imaging follow-up, or a combination of the two had to be used as a reference standard to identify pseudoprogression or true tumour progression in patients with a form of imaging progression. In the cases where a definitive diagnosis could not be established, progression was classified as unknown.

Exclusion criteria included patients with recurrent disease. Any patient group or study that did not follow the characteristics described in the inclusion criteria above, like a group of mixed high- and low-grade gliomas, were also excluded. Studies exploring gliomas of the cranial nerves and spine were excluded. Finally, use of new therapies was also excluded due to our interest in the standard patient group.

\section{Study Selection, Data Extraction and Quality Assessment}

Main data extracted were the number of patients with any form of progression on MRI, the number of patients with pseudoprogression and the number of patients with tumour progression. General study characteristics were also extracted. These included study design, total number of patients, percentage of males, patients' age with range, reference standard (histology and/or follow-up), definition of tumour progression and pseudoprogression, image protocol, and interval between end of therapy and progression. Quality of included studies was assessed with the NIH Quality Assessment Tool by two authors independently [10]. The NIH Quality Assessment tool was divided into four domains. These included the general study setup (questions 1 and 14), the patient selection domain (questions 2-5), the follow-up domain (question 7) and the reference standard domain (questions 11 and 13). Questions 6, 7, 10 and 11 were excluded. These questions were considered non applicable, as the exposure that was referred to was similar for all patients as we included only patients after standard treatment.

\section{Statistical Analysis}

Meta-analysis was performed using data extracted from each study. SPSS version 23 (IBM Inc., Armonk, NY, USA) was employed to calculate the general patient char- 


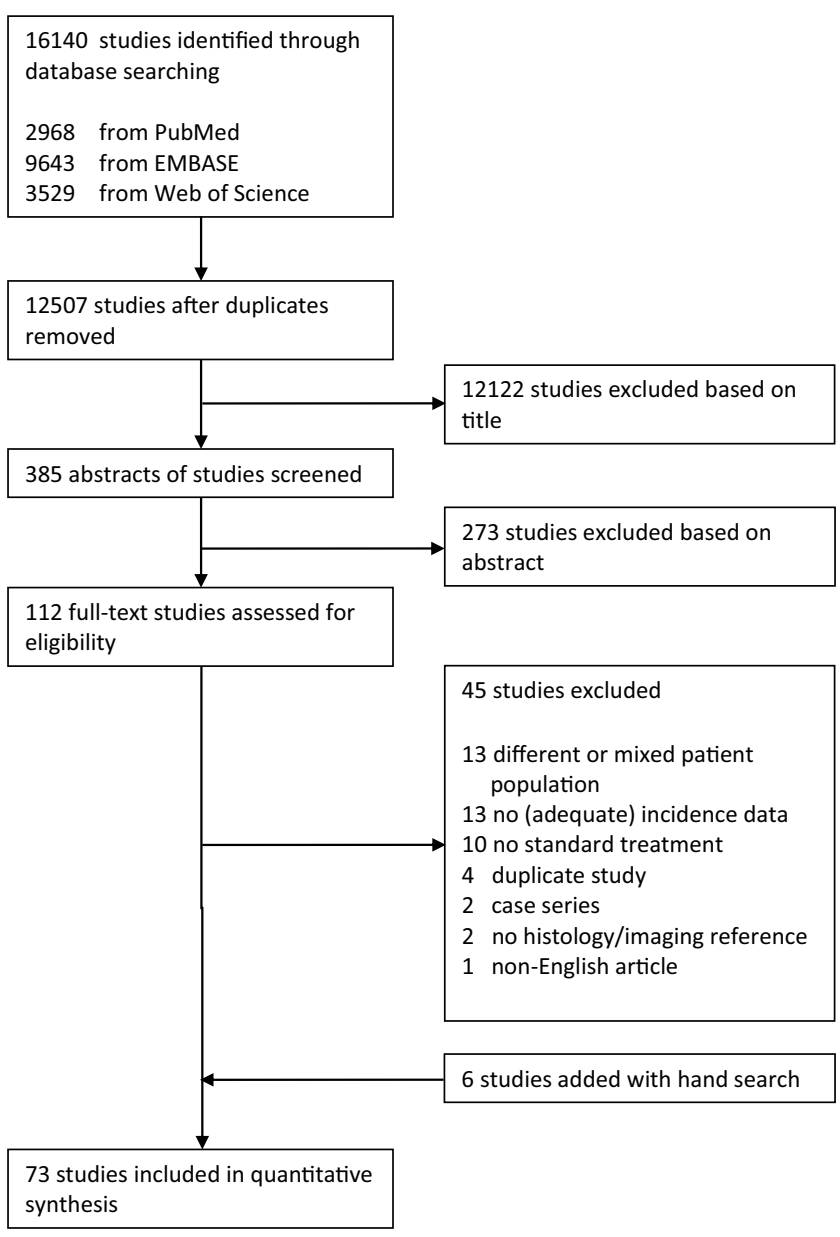

Fig. 1 Flowchart demonstrating the inclusion and exclusion of studies

acteristics. The incidence of patients with tumour progression, pseudoprogression or unknown progression was calculated per study. Subsequently, pooled results of tumour progression and pseudoprogression incidences were calculated using Metaprop in STATA/SE 12.1 (College station, TX, USA) [11]. Studies were weighted according to their variance and the sample size. The $\mathrm{I}^{2}$ test was used to calculate the heterogeneity of the included studies. As this demonstrated a heterogeneous study set, a random effects model was utilised to calculated pooled estimates.

\section{Role of Funding Source}

The funder of the study had no role in study design, data collection, data analysis, data interpretation or report writing. The corresponding author had full access to all data in the study and had final responsibility for the decision to submit for publication.

\section{Results}

\section{General Description of Selection and Included Studies}

We started with 12,507 unduplicated studies. Among the 112 articles that were reviewed in depth, a total of 67 studies met the eligibility criteria and were included in the metaanalysis [12-78]. Additionally, six articles [79-84] were identified with a hand search, leading to a total of 73 included studies (Fig. 1 and appendix for table 1). Fifteen abstracts were included (21\%) [12, 25, 31, 32, 36, 38, 45, $51,53,58,60,66,71,73,76]$.

The included studies concerned 3781 patients with a mean age of 54 years. Of all patients, $57 \%$ were male. The studies included $89 \%$ WHO grade IV astrocytomas (glioblastomas), 7\% WHO grade III astrocytomas (anaplastic astrocytomas) and no specification in $4 \%$ of the patients. In the majority of the patients (75\%), imaging follow-up was used as the reference standard. Histology was utilised in $20 \%$ of the patients. A combination of both histopathology and imaging follow-up was used in $2 \%$ of the patients (see supplementary table 1 for details including the definitions of tumour progression and pseudoprogression). Clinical follow-up alone was used in 3 patients $(0.09 \%)$, while it was unknown for two studies with a total of 94 patients $(2.7 \%)[45,58]$. Sufficient data was provided in 40 studies to calculate the average follow-up period after initial progression on imaging, with a mean follow-up of 14 months (range 1-67 months).

\section{Quality of Included Studies}

A summary of the methodological quality assessment of the included articles is presented in Fig. 2. For the general study setup, a moderate risk was identified. No statistical analysis for potential confounding variables like follow-up duration, MGMT status or used reference standard was performed in $36(49 \%)$ studies and they were thus classified as high risk $[12,15,16,18,29,30,32-36,38-41,43,45,47,50,51,54$, $55,57,59,64,66,70,71,73,76,79-82,84]$. The remaining $37(51 \%)$ studies showed no risk for these questions [13, 14, 17, 19-28, 31, 37, 42, 44, 46, 48, 49, 52, 53, 56, 57, $59,61-63,65,67-69,72,73,75,77,78,83]$.

In the patient selection domain, all articles were classified as high-risk due to the fact that no article had mentioned sample size calculation or power discussion, nor variance or estimate of effect size (question 5 of NIH assessment tool). As the influence of this item on the quality was considered negligible, the patient domain was approached after removing question 5 . This resulted in a much lower risk classification with a total of $27(37 \%)$ high-risk studies. Lacking information pertaining to the number of WHO III and IV tumours [65], as well as age; [21], sex [24, 34, 
Fig. 2 Quality assessment of included studies. The risk of bias in four different domains and concerns about applicability are shown for the included studies. High risk (red - ), unclear risk (yellow ?) and low risk (green + )

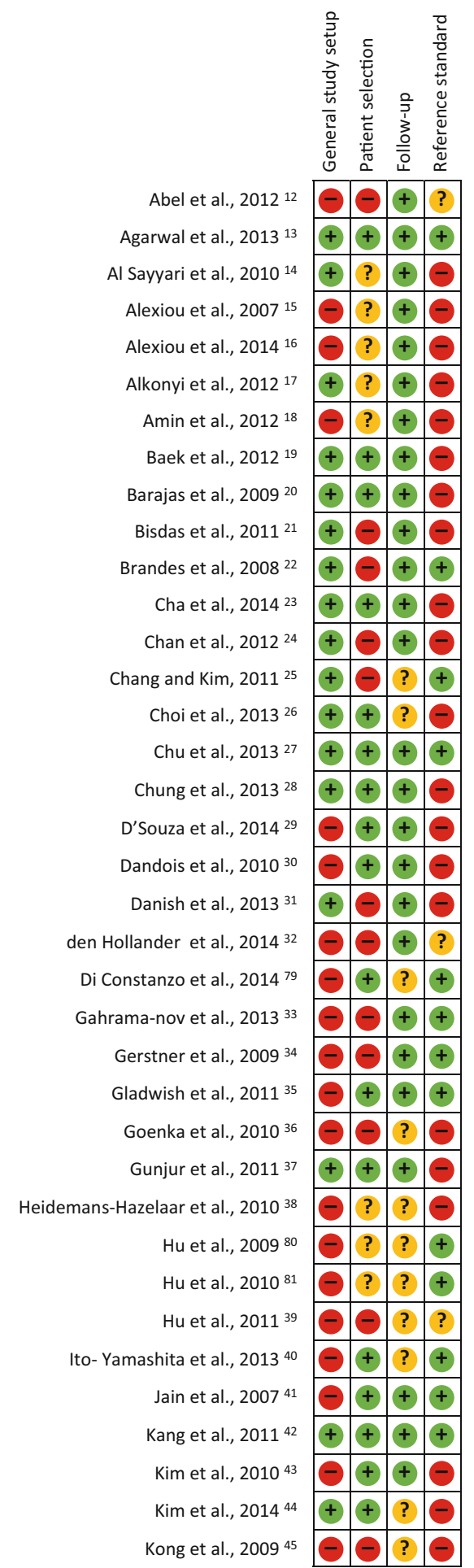

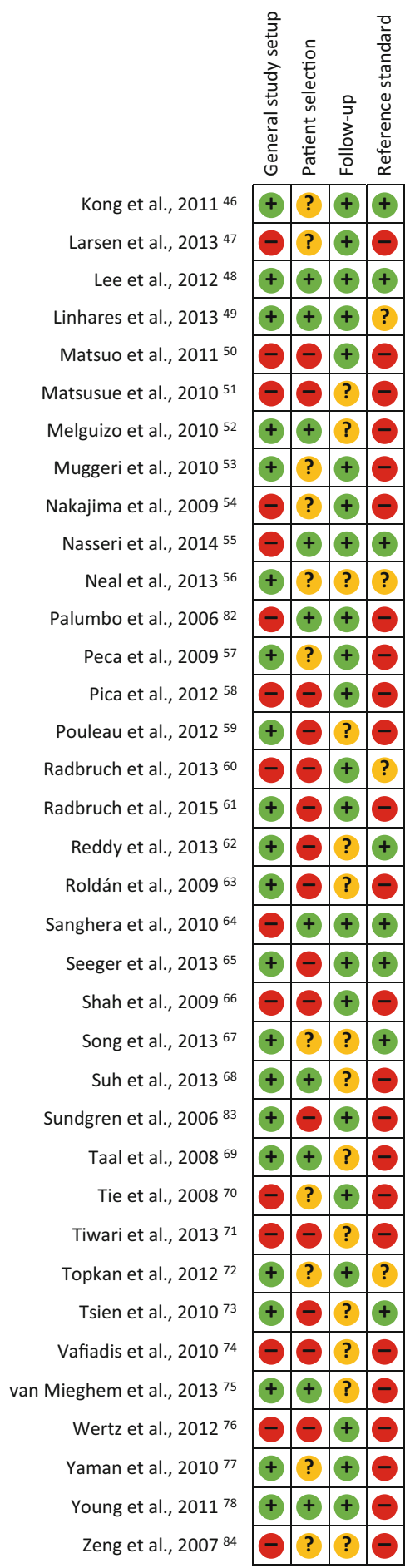

$45,73]$, or the latter two [31-33, 39, 50, 58, 60, 61, 71, $76]$ or three items [12, 25, 36, 74], resulted in a high-risk classification in 20 studies. A participation rate below $50 \%$ resulted in an additional 7 high risk studies $[22,51,59,62$, $63,66,83]$. Unclear risk was seen in $19(26 \%)$ studies, as the participation rate was not reported $[14-18,38,46,53$, $54,56,57,67,70,72,77,80,81,84]$. Low risk was present in the remaining 27 studies $(37 \%)[13,19,20,23,26-30$, $35,37,40-44,48,49,52,55,64,68,69,75,78,79,82]$.

In the follow-up domain, the average quality assessment was good. A total of 25 studies (34\%) were unclear about the follow-up duration $[25,26,36,38-40,44,45,51,52$, $56,59,62,63,67-69,71,73-75,79-81,83]$, while the remaining $48(66 \%)$ were low risk, utilising a sufficient time 
Fig. 3 Forest plot of pooled incidences for treatment induced pseudoprogression. Squares represent the weighted estimate with the solid line indicating the $95 \%$ CI. The dashed line represents the group estimate

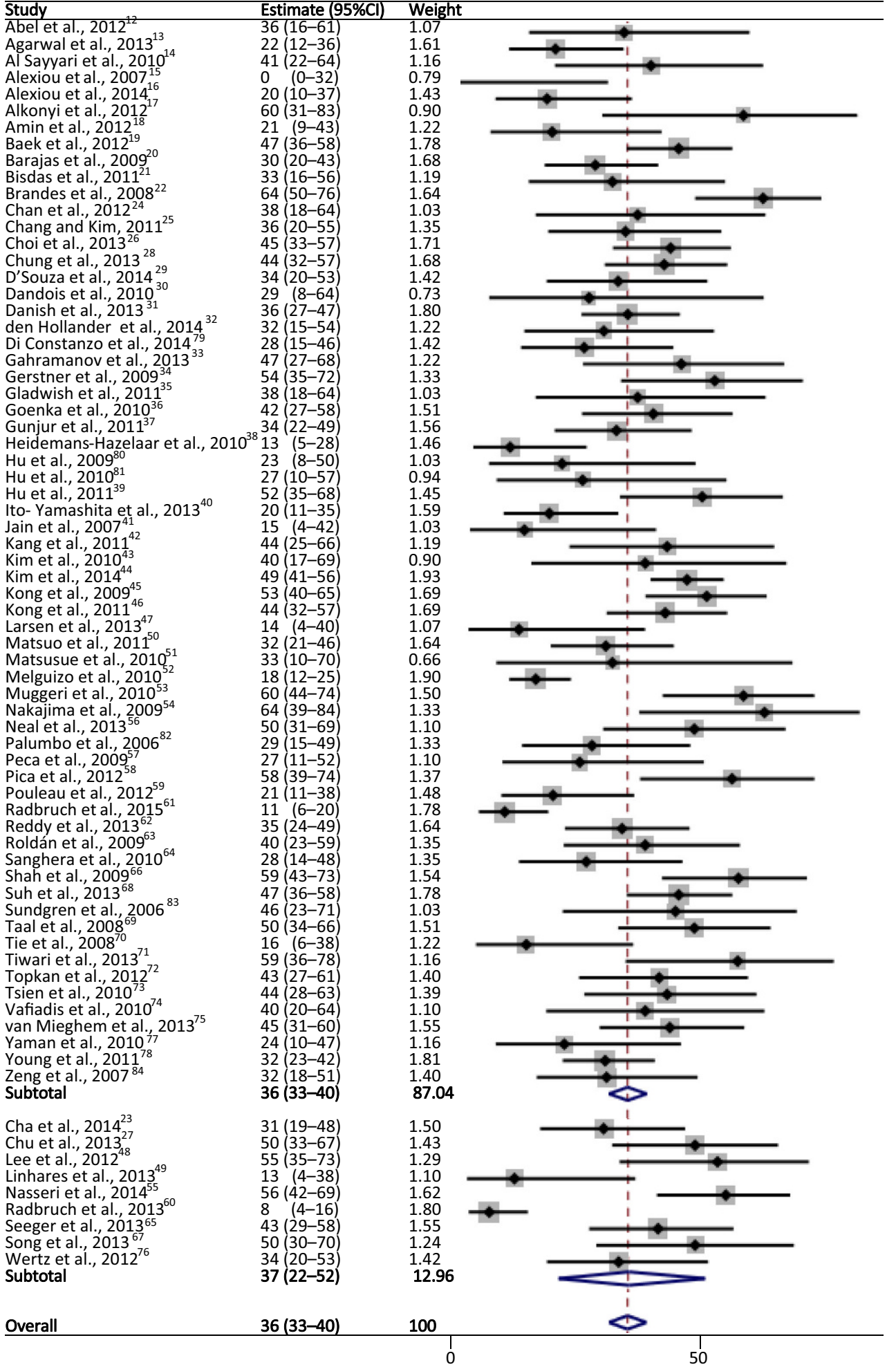

window to classify patients as presenting with either tumour progression or treatment-related progression [12-24, $27-35,37,41-43,46-50,53-55,57,58,60,61,63-66,70$, 72, 76-78, 82, 83].

For the reference standard domain, the overall assessment was deemed a moderate risk. Overall, 45 (62\%) stud- ies were high risk. A total of 8 did not report on reference standard in sufficient detail $[45,50,53,54,57,58,71$, 82], 23 studies did not apply the same reference (histology and/or imaging) to all subjects [14, 17-21, 23, 29, 37, $38,43,44,47,51,52,66,68,69,74,77,78,83,84]$ and 6 studies did not contain the latter two items [15, 16, 26, 
$30,36,70]$. A lost to follow-up rate $>20 \%$ resulted in highrisk classification of another 8 studies [24, 28, 31, 59, 61, $63,75,76]$. The lost to follow-up rate was unclear in 7 studies $(10 \%)$, resulting in an unclear risk $[12,32,39,49,56$, $60,72]$. The remaining $21(29 \%)$ studies were considered low risk with respect to these items $[13,22,25,27,33-35$, 40-42, 46, 48, 55, 62, 64, 65, 67, 73, 79-81].

\section{Heterogeneity}

The $I^{2}$ index demonstrated that the included studies were heterogeneous for the incidence of pseudoprogression $(p<$ $0.01, I^{2}=79 \%$ ) and for the incidence of tumour progression $\left(p<0.01, I^{2}=82 \%\right)$. To account for this heterogeneity, a random effects model was utilised for the analyses of pooled results.

\section{Incidence of Pseudoprogression and Tumour Progression}

Of the total number of included patients in all studies, 2603 patients displayed some form of worsening of imaging findings, demonstrating increased or new enhancement on postcontrast $\mathrm{T} 1$ or progression of high signal on T2/FLAIR imaging according to the RANO criteria (Fig. 3). Of these patients with progression, 36\% (95\%CI 33-40\%) displayed pseudoprogression due to treatment effects. A total of $60 \%$ (95\%CI 56-64\%) of the patients with progression were diagnosed with true tumour progression. The remaining $4 \%$ of patients spread over 12 studies showed an unknown outcome (range $1-37 \%)$. In a subset of 9 studies $(N=295)$, where the use of the RANO criteria to identify progression was specifically stated $[23,27,48,49,55,60,65$, $67,76]$, the pooled results were similar, with $37 \%$ (95\% CI $22-52 \%$ ) of the patients showing pseudoprogression. Furthermore, heterogeneity testing results for the RANO group and the other studies were similar $(p=1.00)$, justifying the pooling of both groups. Comparing the abstract only studies with the others full-text studies showed no clear difference looking at the forest plot.

The interval between the end of concomitant chemoradiotherapy and the time of tumour progression or pseudoprogression on imaging was available for 11 studies, including 265 patients with tumour progression and 204 patients with pseudoprogression. The mean interval was 10.5 months (range 1.7-37.6 months) for tumour progression. For pseudoprogression the interval was 13.0 months on average (range 1.2-40.0 months).

\section{Discussion}

Worsening of imaging findings on postcontrast $\mathrm{T} 1$ or high T2/FLAIR MRI can be attributed to tumour progression or pseudoprogression, but the distribution of both was highly uncertain prior to this study. Our meta-analysis has shown that across the available literature, pseudoprogression occurred, on average, in $36 \%$ of the patients with a highgrade glioma, while tumour progression occurs in $60 \%$.

The finding that $36 \%$ of the patients presenting with progression is due to pseudoprogression confirms what many experts in the field suspect; pseudoprogression is a frequently occurring entity. However, it is above rates stated commonly in the literature. For instance, an elaborate review indicated that pseudoprogression can occur in up to $20 \%$ of patients treated with standard temozolomide chemoradiotherapy [3], with a reported range of 3-24\%. Previous studies providing incidence data have based their findings on a limited number of studies while utilising a non-systematic search approach. Considering the large amount of available data, it is also hard to do it differently, unless a full meta-analysis is conducted. Our meta-analysis is thus the first study to combine the data from all the available literature to estimate an incidence reflecting the full extent of the available literature. This is also the first study to specifically calculate pseudoprogression incidence consistently for all studies only including patients with some form of imaging progression. Including patients without any imaging progression would have resulted in lower and hard-to-interpret numbers which cannot be compared with other studies easily.

The occurrence of neurological deficits due to tumour progression or recurrence on MR imaging has been reported to be accompanied by the presence of oedema [85], which was already demonstrated in 1979 [86]. In that study, it was noted that $28 \%$ of the patients spontaneously improved without a change in prescribed therapy. This is now recognised as being due to pseudoprogression. The pathophysiology of pseudoprogression remains unclear. Demyelination was discussed as a probable factor [87]. A more commonly used explanation is the increased capillary permeability induced by radiotherapy [88]. In conjunction with its disruption, upregulation of signalling proteins also affects the permeability of the blood-brain barrier [89]. This metaanalysis, to our knowledge, collates separate observations of all previous literature for the first time, to provide a more complete overview of progression in the context of highgrade glioma treatment.

By clarifying the full extent of the known limitations, this meta-analysis will enable clinicians to more carefully interpret posttreatment conventional MRI imaging in patients showing progression. Supplementary research is needed to improve the differentiation between true tumour progres- 
sion and pseudoprogression. This could be achieved using more advanced MRI and/or PET imaging to visualise the biological activity of tissue. Firstly, this improved knowledge is needed for deciding which patients do not benefit from the treatment given. The therapy and its side-effects can be discontinued and a switch to a second-line treatment could be considered. Secondly, new immunotherapies or antiangiogenic medications present new problems in the judgment of progression on anatomical MRI [90]. Thus, further research on functional imaging for treatment follow-up is paramount.

This review was limited due to the nature of the available literature. Most importantly, defining tumour progression and pseudoprogression is challenging. This is reflected in the variability in the definitions used in the included studies (see supplementary table 1). However, all studies used histology or imaging follow-up that needed to show some form of stabilisation or improvement in cases with pseudoprogression, which are adequate definitions. Some of the abstract-only studies that were included to prevent publication bias provided no clear definition. This was reflected in the moderate quality assessed with the NIH quality assessment tool. The retrospective nature of some included studies was also a limitation affecting the NIH quality assessment scores. None of the studies reported on power or sample sizes. This is because observational studies are often exploratory in nature. However, the risk of an insufficient sample size is overcome by the benefits of this metaanalysis combining all studies.

In conclusion, this meta-analysis showed that, across the available literature weighted by importance, pseudoprogression occurred frequently $(36 \%)$ in patients with a highgrade glioma following standard chemoradiotherapy. Tumour progression occurred in $60 \%$ of the patients with some form of imaging progression. This meta-analysis thus showed the full extent of the problem in differentiating pseudoprogression from tumour progression, helping pave the way towards more research to improve imaging methods for reliable treatment decision making.

Acknowledgements This study was supported by a Mandema Stipendium (AH) and JSM pilot grant (AA) from the University of Groningen.

Funding This study was funded by a Mandema stipendium from the University of Groningen (AH) and a Junior Scientific Masterclass pilot grant for the University of Groningen (AA).

\section{Compliance with ethical guidelines}

Conflict of interest A.W. Abbasi, H.E. Westerlaan, G.A. Holtman, K.M. Aden, P.J. van Laar and A. van der Hoorn declare that they have no competing interests.
Ethical standards This article does not contain any studies with human participants or animals performed by any of the authors.

Open Access This article is distributed under the terms of the Creative Commons Attribution 4.0 International License (http:// creativecommons.org/licenses/by/4.0/), which permits unrestricted use, distribution, and reproduction in any medium, provided you give appropriate credit to the original author(s) and the source, provide a link to the Creative Commons license, and indicate if changes were made.

\section{Appendix}

\section{Search Strategy}

Search Strategy MEDLINE Via PubMed

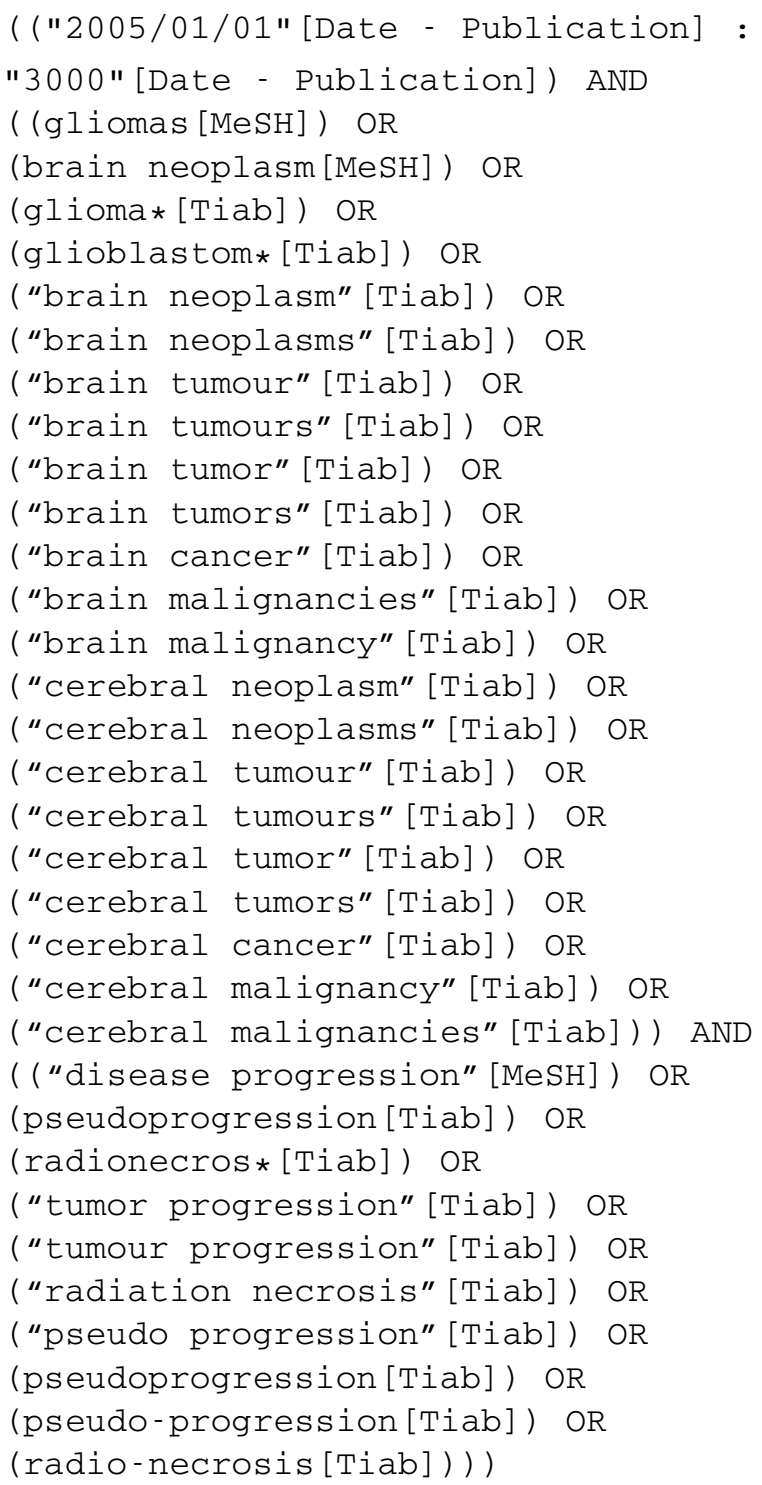




\section{Search Strategy EMBASE Via EMBASE}

\author{
([2005-2014]/py) AND ('glioma'/exp OR \\ brain cancer'/exp OR glioma:ab,ti OR \\ glioblastoma: ab, ti OR \\ brain neoplasma':ab, ti OR \\ brain neoplasmas':ab, ti OR \\ 'brain cancer':ab, ti OR \\ 'brain malignancy':ab, ti OR \\ 'brain malignancies':ab, ti OR \\ brain tumor':ab, ti OR \\ brain tumour':ab, ti OR \\ brain tumors':ab, ti OR \\ brain tumours':ab, ti OR \\ cerebral neoplasma':ab,ti OR \\ cerebral neoplasmas':ab,ti OR \\ cerebral tumor':ab,ti OR \\ cerebral tumour':ab,ti OR \\ cerebral tumors':ab, ti OR \\ cerebral tumours':ab,ti OR \\ 'cerebral cancer':ab,ti OR \\ 'cerebral malignancy':ab,ti OR \\ 'cerebral malignancies':ab,ti) AND \\ ('tumor growth'/exp OR \\ radiation necrosis'/exp OR \\ cancer growth'/exp OR \\ disease progression':ab,ti OR \\ pseudoprogression':ab,ti OR \\ 'pseudo-progression' : ab, ti OR \\ 'radio-necrosis':ab,ti OR \\ radionecros*:ab, ti OR \\ tumor progression':ab,ti OR \\ tumour progression':ab,ti OR \\ radiation necrosis':ab, ti OR \\ pseudoprogression':ab,ti)
}

\section{Search Strategy Web of Science Via Web of Knowledge}

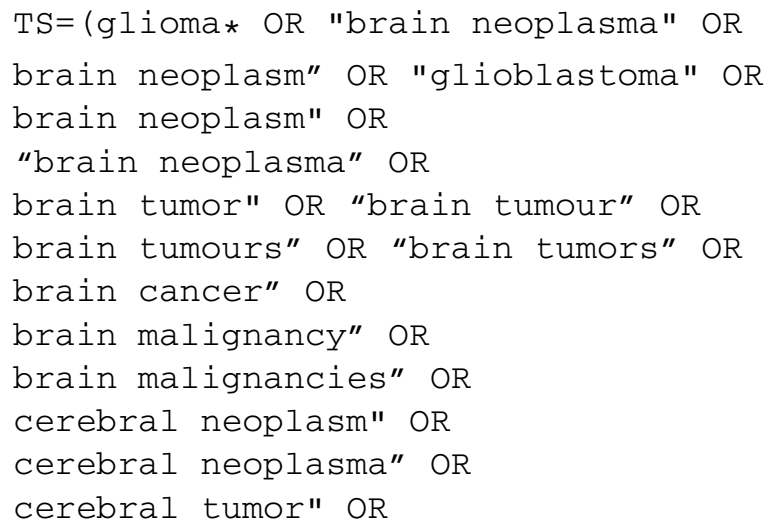

cerebral tumour" OR

cerebral tumors" OR

cerebral tumours" OR

cerebral cancer" OR

cerebral malignancies" OR

cerebral malignancy") AND

$\mathrm{TS}=($ "disease progression" OR

pseudoprogression" OR

radionecrosis" OR

tumor progression" OR

tumour progression" OR

radiation necrosis" OR

pseudo progression" OR

pseudo-progression" OR

radio-necrosis")

\section{References}

1. Stupp R, Mason WP, van den Bent MJ, Weller M, Fisher B, Taphoorn MJ, Belanger K, Brandes AA, Marosi C, Bogdahn U, Curschmann J, Janzer RC, Ludwin SK, Gorlia T, Allgeier A, Lacombe D, Cairncross JG, Eisenhauer E, Mirimanoff RO; European Organisation for Research and Treatment of Cancer Brain Tumor and Radiotherapy Groups; National Cancer Institute of Canada Clinical Trials Group. Radiotherapy plus concomitant and adjuvant temozolomide for glioblastoma. N Engl J Med. 2005;352:987-96.

2. Wen PY, Macdonald DR, Reardon DA, Cloughesy TF, Sorensen AG, Galanis E, Degroot J, Wick W, Gilbert MR, Lassman AB, Tsien C, Mikkelsen T, Wong ET, Chamberlain MC, Stupp R, Lamborn KR, Vogelbaum MA, van den Bent MJ, Chang SM. Updated response assessment criteria for high-grade gliomas: response assessment in neuro-oncology working group. J Clin Oncol. 2010;28:1963-72.

3. Brandsma D, Stalpers L, Taal W, Sminia P, van den Bent MJ. Clinical features, mechanisms, and management of pseudoprogression in malignant gliomas. Lancet Oncol. 2008;9:453-61.

4. de Wit MC, de Bruin HG, Eijkenboom W, Sillevis Smitt PA, van den Bent MJ. Immediate post-radiotherapy changes in malignant glioma can mimic tumor progression. Neurology. 2004;63:535-7.

5. Chaskis C, Neyns B, Michotte A, De Ridder M, Everaert H. Pseudoprogression after radiotherapy with concurrent temozolomide for high-grade glioma: clinical observations and working recommendations. Surg Neurol. 2009;72:423-8.

6. Taal W, Brandsma D, de Bruin HG, Bromberg JE, Swaak-Kragten AT, Smitt PA, van Es CA, van den Bent MJ. Incidence of early pseudo-progression in a cohort of malignant glioma patients treated with chemoirradiation with temozolomide. Cancer. 2008;113:405-10.

7. Stroup DF, Berlin JA, Morton SC, Olkin I, Williamson GD, Rennie D, Moher D, Becker BJ, Sipe TA, Thacker SB. Meta-analysis of observational studies in epidemiology: a proposal for reporting. Meta-analysis Of Observational Studies in Epidemiology (MOOSE) group. JAMA. 2000;283:2008-12.

8. Liberati A, Altman DG, Tetzlaff J, Mulrow C, Gøtzsche PC, Ioannidis JP, Clarke M, Devereaux PJ, Kleijnen J, Moher D. The PRISMA statement for reporting systematic reviews and meta-analyses of studies that evaluate healthcare interventions: explanation and elaboration. BMJ. 2009;339:b2700.

9. Shea BJ, Hamel C, Wells GA, Bouter LM, Kristjansson E, Grimshaw J, Henry DA, Boers M. AMSTAR is a reliable and valid mea- 
surement tool to assess the methodological quality of systematic reviews. J Clin Epidemiol. 2009;62:1013-20.

10. NHLBI, NIH. Quality assessment tool for observational cohort and cross-sectional studies 2014. http://www.nhlbi.nih.gov/health-pro/ guidelines/in-develop/cardiovascular-risk-reduction/tools/cohort. Accessed 15 Dec 2015.

11. Nyaga VN, Arbyn M, Aerts M. Metaprop: a Stata command to perform meta-analysis of binomial data. Arch Public Health. 2014;72:39.

12. Abel R, Jones J, Mandelin P, Cen S, Pagnini P. Distinguishing pseudoprogression from true progression by FLAIR volumetric characteristics compared to $45 \mathrm{~Gy}$ isodose volumes in treated glioblastoma patients. Int J Radiat Oncol Biol Phys. 2012;84:S275.

13. Agarwal A, Kumar S, Narang J, Schultz L, Mikkelsen T, Wang S, Siddiqui S, Poptani H, Jain R. Morphologic MRI features, diffusion tensor imaging and radiation dosimetric analysis to differentiate pseudo-progression from early tumor progression. J Neurooncol. 2013;112:413-20.

14. Al Sayyari A, Buckley R, McHenery C, Pannek K, Coulthard A, Rose S. Distinguishing recurrent primary brain tumor from radiation injury: a preliminary study using a susceptibility-weighted MR imaging-guided apparent diffusion coefficient analysis strategy. AJNR Am J Neuroradiol. 2010;31:1049-54.

15. Alexiou GA, Fotopoulos AD, Papadopoulos A, Kyritsis AP, Polyzoidis KS, Tsiouris S. Evaluation of brain tumor recurrence by 99mTc-tetrofosmin SPECT: a prospective pilot study. Ann Nucl Med. 2007;21:293-8.

16. Alexiou GA, Zikou A, Tsiouris S, Goussia A, Kosta P, Papadopoulos A, Voulgaris S, Tsekeris P, Kyritsis AP, Fotopoulos AD, Argyropoulou MI. Comparison of diffusion tensor, dynamic susceptibility contrast MRI and 99mTc-Tetrofosmin brain SPECT for the detection of recurrent high-grade glioma. Magn Reson Imaging. 2014;32:854-9.

17. Alkonyi B, Barger GR, Mittal S, Muzik O, Chugani DC, Bahl G, Robinette NL, Kupsky WJ, Chakraborty PK, Juhász C. Accurate differentiation of recurrent gliomas from radiation injury by kinetic analysis of -11C-Methyl-L-Tryptophan PET. J Nucl Med. 2012;53:1058-64.

18. Amin A, Moustafa H, Ahmed E, El-Toukhy M. Glioma residual or recurrence versus radiation necrosis: accuracy of pentavalent technetium-99m-dimercaptosuccinic acid [Tc-99m (V) DMSA] brain SPECT compared to proton magnetic resonance spectroscopy $(1 \mathrm{H}-$ MRS): initial results. J Neurooncol. 2012;106:579-87.

19. Baek HJ, Kim HS, Kim N, Choi YJ, Kim YJ. Percent change of perfusion skewness and kurtosis: a potential imaging biomarker for early treatment response in patients with newly diagnosed glioblastomas. Radiology. 2012;264:834-43.

20. Barajas RF, Chang JS, Segal MR, Parsa AT, McDermott MW, Berger MS, Cha S. Differentiation of recurrent glioblastoma multiforme from radiation necrosis after external beam radiation therapy with dynamic susceptibility-weighted contrast-enhanced perfusion MR imaging. Radiology. 2009;253:486-96.

21. Bisdas S, Naegele T, Ritz R, Dimostheni A, Pfannenberg C, Reimold M, Koh TS, Ernemann U. Distinguishing recurrent highgrade gliomas from radiation injury. Acad Radiol. 2011;18:575-83.

22. Brandes AA, Franceschi E, Tosoni A, Blatt V, Pession A, Tallini G, Bertorelle R, Bartolini S, Calbucci F, Andreoli A, Frezza G, Leonardi M, Spagnolli F, Ermani M. MGMT promoter methylation status can predict the incidence and outcome of pseudoprogression after concomitant radiochemotherapy in newly diagnosed glioblastoma patients. J Clin Oncol. 2008;26:2192-7.

23. Cha J, Kim ST, Kim HJ, Kim BJ, Kim YK, Lee JY, Jeon P, Kim $\mathrm{KH}$, Kong DS, Nam DH. Differentiation of tumor progression from pseudoprogression in patients with posttreatment glioblastoma using multiparametric histogram analysis. AJNR Am J Neuroradiol. 2014;35:1309-17.
24. Chan DT, Ng RYT, Siu DYW, Tang P, Kam MKM, Ma BBY, Wong GKC, Ng SCP, Pang JCS, Lau CKY, Zhu XL, Ng HK, Poon WS. Pseudoprogression of malignant glioma in Chinese patients receiving concomitant chemoradiotherapy. Hong Kong Med J. 2012;18:221-5.

25. Chang J, Kim I. Pseudoprogression and pseudoresponse in the management of high-grade glioma: analysis based on the new criteria of the neuro-oncology working group. Int J Radiat Oncol. 2011;81:S273.

26. Choi YJ, Kim HS, Jahng GH, Kim SJ, Suh DC. Pseudoprogression in patients with glioblastoma: added value of arterial spin labeling to dynamic susceptibility contrast perfusion MR imaging. Acta Radiol. 2013;54:448-54.

27. Chu HH, Choi SH, Ryoo I, Kim SC, Yeom JA, Shin H, Jung SC, Lee AL, Yoon TJ, Kim TM, Lee SH, Park CK, Kim JH, Sohn CH, Park SH, Kim IH. Differentiation of true progression from pseudoprogression in glioblastoma treated with radiation therapy and concomitant temozolomide: comparison study of standard and high-bvalue diffusion-weighted imaging. Radiology. 2013;269:831-40.

28. Chung WJ, Kim HS, Kim N, Choi CG, Kim SJ. Recurrent glioblastoma: optimum area under the curve method derived from dynamic contrast-enhanced T1-weighted perfusion MR imaging. Radiology. 2013;269:561.

29. D'Souza MM, Sharma R, Jaimini A, Panwar P, Saw S, Kaur P, Mondal A, Mishra A, Tripathi RP. 11C-MET PET/CT and advanced MRI in the evaluation of tumor recurrence in high-grade gliomas. Clin Nucl Med. 2014;39:791-8.

30. Dandois V, Rommel D, Renard L, Jamart J, Cosnard G. Substitution of $11 \mathrm{C}$-methionine PET by perfusion MRI during the follow-up of treated high-grade gliomas: preliminary results in clinical practice. J Neuroradiol. 2010;37:89-97.

31. Danish H, Schreibmann E, Holder C, Vincentelli C, Hao C, Curran W, Fox T, Crocker I, Shu HG. Postradiation diffusion MRIs may distinguish true progression from pseudoprogression in GBM patients. Int J Radiat Oncol Biol Phys. 2013;87:S19.

32. den Hollander MW, Enting RH, de Groot JC, Solouki MA, den Dunnen WFA, Sluiter WJ, Heesters MAAM, Wagemakers M, Gietema JA, de Vries E, Pruim J, Walenkamp AME. Prospective analysis of serial FLT-PET scanning to discriminate between true and pseudoprogression in glioblastoma. J Clin Oncol. 2014;32:S5.

33. Gahramanov S, Muldoon LL, Varallyay CG, Li X, Kraemer DF, Fu R, Hamilton BE, Rooney WD, Neuwelt EA. Pseudoprogression of glioblastoma after chemo- and radiation therapy: diagnosis by using dynamic susceptibility-weighted contrast-enhanced perfusion MR imaging with Ferumoxytol versus Gadoteridol and correlation with survival. Radiology. 2013;266:842-52.

34. Gerstner ER, McNamara MB, Norden AD, LaFrankie D, Wen PY. Effect of adding temozolomide to radiation therapy on the incidence of pseudo-progression. J Neurooncol. 2009;94:97-101.

35. Gladwish A, Koh ES, Hoisak J, Lockwood G, Millar BA, Mason W, Yu E, Laperriere NJ, Ménard C. Evaluation of early imaging response criteria in glioblastoma multiforme. Radiat Oncol. 2011;6:121.

36. Goenka A, Kumar A, Sharma R, Seith A, Kumar R, Julka P. Differentiation of glioma progression or recurrence from treatment-induced changes using a combination of diffusion, perfusion and 3D-MR spectroscopy: a prospective study. J Neuroimaging. 2010;20:99-100.

37. Gunjur A, Lau E, Taouk Y, Ryan G. Early post-treatment pseudoprogression amongst glioblastoma multiforme patients treated with radiotherapy and temozolomide: a retrospective analysis. J Med Imaging Radiat Oncol. 2011;55:603-10.

38. Heidemans-Hazelaar C, Verbeek AY, Oosterkamp HM, van der Kallen B, Vecht CJ. Use of perfusion MR imaging for differentiation between tumor progression and pseudo-progression in recurrent glioblastoma multiforme. J Clin Oncol. 2010;28:S2. 
39. Hu X, Wong KK, Young GS, Guo L, Wong ST. Support vector machine multiparametric MRI identification of pseudoprogression from tumor recurrence in patients with resected glioblastoma. J Magn Reson Imaging. 2011;3:296-305.

40. Ito-Yamashita T, Nakasu Y, Mitsuya K, Mizokami Y, Namba H. Detection of tumor progression by signal intensity increase on fluidattenuated inversion recovery magnetic resonance images in the resection cavity of high-grade gliomas. Neurol Med Chir (Tokyo). 2013;53:496-500.

41. Jain R, Scarpace L, Ellika S, Schultz LR, Rock JP, Rosenblum ML, Patel SC, Lee TY, Mikkelsen T. First-pass perfusion computed tomography: initial experience in differentiating recurrent brain tumors from radiation effects and radiation necrosis. Neurosurgery. 2007;61:778-87.

42. Kang HC, Kim CY, Han JH, Choe GY, Kim JH, Kim JH, Kim IA. Pseudoprogression in patients with malignant gliomas treated with concurrent temozolomide and radiotherapy: potential role of p53. J Neurooncol. 2011;102:157-62.

43. Kim YH, Oh SW, Lim YJ, Park CK, Lee SH, Kang KW, Jung $\mathrm{HW}$, Chang KH. Differentiating radiation necrosis from tumor recurrence in high-grade gliomas: assessing the efficacy of 18F-FDG PET, 11C-methionine PET and perfusion MRI. Clin Neurol Neurosurg. 2010;112:758-65.

44. Kim HS, Goh MJ, Kim N, Choi CG, Kim SJ, Kim JH. Which combination of MR imaging modalities is best for predicting recurrent glioblastoma? Study of diagnostic accuracy and reproducibility. Radiology. 2014;273:831-43.

45. Kong DS, Kim ST, Lee JI, Park K, Kim JH, Nam DH. Dynamic perfusion MR images can predict the pseudoprogression mimicking true progression in the treatment of newly diagnosed glioblastoma. Neuro Oncol. 2009;11:893.

46. Kong DS, Kim ST, Kim EH, Lim DH, Kim WS, Suh YL, Lee JI, Park K, Kim JH, Nam DH. Diagnostic dilemma of pseudoprogression in the treatment of newly diagnosed glioblastomas: the role of assessing relative cerebral blood flow volume and oxygen-6methylguanine-DNA methyltransferase promoter methylation status. AJNR Am J Neuroradiol. 2011;32:382-7.

47. Larsen VA, Simonsen HJ, Law I, Larsson HBW, Hansen AE. Evaluation of dynamic contrast-enhanced T1-weighted perfusion MRI in the differentiation of tumor recurrence from radiation necrosis. Neuroradiology. 2012;55:361-9.

48. Lee WJ, Choi SH, Park CK, Yi KS, Kim TM, Lee SH, Kim JH, Sohn CH, Park SH, Kim IH. Diffusion-weighted MR imaging for the differentiation of true progression from pseudoprogression following concomitant radiotherapy with temozolomide in patients with newly diagnosed high-grade gliomas. Acad Radiol. 2012;19:1353-61.

49. Linhares P, Carvalho B, Figueiredo R, Reis RM, Vaz R. Early pseudoprogression following chemoradiotherapy in glioblastoma patients: the value of RANO evaluation. J Oncol. 2013;2013:690585.

50. Matsuo M, Miwa K, Shinoda J, Tanaka O, Krishna M. Impact of C11-methionine positron emission tomography (PET) for malignant glioma in radiation therapy: Is C11-methionine PET a superior to magnetic resonance imaging? Int J Radiat Oncol Biol Phys. 2011;81:S182.

51. Matsusue E, Fink JR, Rockhill JK, Ogawa T, Maravilla KR. Distinction between glioma progression and post-radiation change by combined physiologic MR imaging. Neuroradiology. 2009;52:297306.

52. Melguizo-Gavilanes I, Bruner JM, Guha-Thakurta N, Hess KR, Puduvalli VK. Characterization of pseudoprogression in patients with glioblastoma: is histology the gold standard? J Neurooncol. 2015;123:141-50.

53. Muggeri AD, Falcon L, Sanchez F, Diez B. Incidence and survival in glioblastoma patients with pseudo-progression in a single institution. Neuro Oncol. 2010;12:iii44.
54. Nakajima T, Kumabe T, Kanamori M, Saito R, Tashiro M, Watanabe M, Tominaga T. Differential diagnosis between radiation necrosis and glioma progression using sequential proton magnetic resonance spectroscopy and methionine positron emission tomography. Neurol Med Chir (Tokyo). 2009;49:394-401.

55. Nasseri M, Gahramanov S, Netto JP, Fu R, Muldoon LL, Varallyay C, Hamilton BE, Neuwelt EA. Evaluation of pseudoprogression in patients with glioblastoma multiforme using dynamic magnetic resonance imaging with ferumoxytol calls RANO criteria into question. Neuro Oncol. 2014;16:1146-54.

56. Neal ML, Trister AD, Ahn S, Baldock A, Bridge CA, Guyman L, Lange J, Sodt R, Cloke T, Lai A, Cloughesy T, Mrugala MM, Rockhill JK, Rockne RC, Swanson KR. Response classification based on a minimal model of glioblastoma growth is prognostic for clinical outcomes and distinguishes progression from pseudoprogression. Cancer Res. 2013;73:2976-86.

57. Peca C, Pacelli R, Elefante A, Del Basso De Caro ML, Vergara P, Mariniello G, Giamundo A, Maiuri F. Early clinical and neuroradiological worsening after radiotherapy and concomitant temozolomide in patients with glioblastoma: tumour progression or radionecrosis? Clin Neurol Neurosurg. 2009;111:331-4.

58. Pica A, Hauf M, Slotboom J, Beck J, Schucht P, Aebersold DM, Wiest R. Dynamic susceptibility contrast perfusion MRI in differentiating radiation necrosis from tumor recurrence in high-grade gliomas. J Neurooncol. 2012;14:iii35-iii36.

59. Pouleau HB, Sadeghi N, Balériaux D, Mélot C, de Witte O, Lefranc F. High levels of cellular proliferation predict pseudoprogression in glioblastoma patients. Int J Oncol. 2012;40:923-8.

60. Radbruch A, Reimer C, Graf M, Fladt J, Deike K, Floca RO, Heiland S, Schlemmer HP, Wick W, Wiestler B. Frequency of pseudoprogression in patients with glioblastoma according to RANO criteria. Neuroradiology. 2013;55:S59.

61. Radbruch A, Fladt J, Kickingereder P, Wiestler B, Nowosielski M, Bäumer P, Schlemmer HP, Wick A, Heiland S, Wick W, Bendszus M. Pseudoprogression in patients with glioblastoma: clinical relevance despite low incidence. Neuro Oncol. 2015;17:151-9.

62. Reddy K, Westerly D, Chen C. MRI patterns of T1 enhancing radiation necrosis versus tumour recurrence in high-grade gliomas. J Med Imaging Radiat Oncol. 2013;57:349-55.

63. Roldán GB, Scott JN, McIntyre JB, Dharmawardene M, de Robles PA, Magliocco AM, Yan ESH, Parney IF, Forsyth PA, Cairncross JG, Hamilton MG, Easaw JC. Population-based study of pseudoprogression after chemoradiotherapy in GBM. Can J Neurol Sci. 2009;36:617-22.

64. Sanghera P, Perry J, Sahgal A, Symons S, Aviv R, Morrison M, Lam K, Davey P, Tsao MN. Pseudoprogression following chemoradiotherapy for glioblastoma multiforme. Can J Neurol Sci. 2010;37:36-42.

65. Seeger A, Braun C, Skardelly M, Paulsen F, Schittenhelm J, Ernemann U, Bisdas S. Comparison of three different MR perfusion techniques and MR spectroscopy for multiparametric assessment in distinguishing recurrent high-grade gliomas from stable disease. Acad Radiol. 2013;20:1557-65.

66. Shah A, Gupta A, Young R, Beal K, Karimi S, Shi W, Zhang Z, Holodny A. Identifying pseudoprogression in glioblastoma: utility of conventional MR findings 2009. Neuro Oncol. 2009;11:673.

67. Song YS, Choi SH, Park CK, Yi KS, Lee WJ, Yun TJ, Kim TM, Lee SH, Kim JH, Sohn CH, Park SH, Kim IH, Jahng GH, Chang $\mathrm{KH}$. True progression versus pseudoprogression in the treatment of glioblastomas: A comparison study of normalized cerebral blood volume and apparent diffusion coefficient by histogram analysis. Korean J Radiol. 2013;14:662-72.

68. Suh CH, Kim HS, Choi YJ, Kim N, Kim SJ. Prediction of pseudoprogression in patients with glioblastomas using the initial and final area under the curves ratio derived from dynamic contrast- 
enhanced T1-weighted perfusion MR imaging. AJNR Am J Neuroradiol. 2013;34:2278-86.

69. Taal W, Brandsma D, de Bruin HG, Bromberg JE, Swaak-Kragten AT, Sillevis Smitt PAE, van Es CA, van den Bent MJ. Incidence of early pseudo-progression in a cohort of malignant glioma patients treated with chemoirradiation with temozolomide. Cancer. 2008;113:405-10.

70. Tie J, Gunawardana DH, Rosenthal MA. Differentiation of tumor recurrence from radiation necrosis in high-grade gliomas using 201Tl-SPECT. J Clin Neurosci. 2008;15:1327-34.

71. Tiwari P, Rogers L, Wolansky L, Sloan A, Barnholtz-Sloan J, Tatsauka C, Cohen M, Madabhushi A. Computerized image analysis of texture descriptors in multi-parametric MRI to distinguish recurrent glioblastoma multiforme from radiation necrosis. Neuro Oncol. 2013;15:iii203.

72. Topkan E, Topuk S, Oymak E, Parlak C, Pehlivan B. Pseudoprogression in patients with glioblastoma multiforme after concurrent radiotherapy and temozolomide. Am J Clin Oncol. 2012;35:284-9.

73. Tsien C, Galbán CJ, Chenevert TL, Johnson TD, Hamstra DA, Sundgren PC, Junck L, Meyer CR, Rehemtulla A, Lawrence T, Ross BD. Parametric response map as an imaging biomarker to distinguish progression from pseudoprogression in high-grade glioma. J Clin Oncol. 2010;28:2293-9.

74. Goericke SL, Schlamann M, Hagenacker T, Gartzen K, Wanke I, Forsting M. A High CSF Signal on FLAIR: It Is Not Always Blood. Neuroradiol J. 2010;23:389-92.

75. van Mieghem E, Wozniak A, Geussens Y, Menten J, De Vleeschouwer S, Van Calenbergh F, Sciot R, Van Gool S, Bechter OE, Demaerel P, Wilms G, Clement PM. Defining pseudoprogression in glioblastoma multiforme. Eur J Neurol. 2013;20:1335-41.

76. Wertz M, Padovani L, Bequet-Boucard C, Barrie M, Matta M, Muracciole X, Chinot O. Is pseudoprogression (PSP) impacted by a very early progression (VEP)? A retrospective cohort study. Neuro Oncol. 14(suppl_3):iii1-iii94

77. Yaman E, Buyukberber S, Bnekli M, Oner Y, Coskun U, Akmansu M, Ozturk B, Kaya AO, Uncu D, Yildiz R. Radiation induced early necrosis in patients with malignant gliomas receiving temozolomide. Clin Neurol Neurosurg. 2010;112:662-7.

78. Young RJ, Gupta A, Shah AD, Graber JJ, Zhang Z, Shi W, Holodny AI, Omuro AMP. Potential utility of conventional MRI signs in diagnosing pseudoprogression in glioblastoma. Neurology. 2011;76:1918-24.

79. Di Costanzo A, Scarabino T, Trojsi F, Popolizio T, Bonavita S, de Cristofaro M, Conforti R, Cristofano A, Colonnese C, Salvolini U, Tedeschi G. Recurrent glioblastoma multiforme versus radi- ation injury: a multiparametric 3-T MR approach. Radiol Med. 2014;119:616-24.

80. Hu LS, Baxter LC, Smith KA, Feuerstein BG, Karis JP, Eschbacker JM, Coons SW, Nakaji P, Yeh RF, Debbins J, Heiserman JE. Relative cerebral blood volume values to differentiate high-grade glioma recurrence from posttreatment radiation effect: direct correlation between image-guided tissue histopathology and localized dynamic susceptibility-weighted contrast-enhanced perfusion MR imaging measurements. AJNR Am J Neuroradiol. 2009;30:552-8.

81. Hu LS, Baxter LC, Pinnaduwage DS, Paine TL, Karis JP, Feuersteine BG, Schmainda KM, Dueck AC, Debbins J, Smith KA, Nakaji P, Eschbacher JM, Coons SW, Heiserman JE. Optimized preload leakage-correction methods to improve the diagnostic accuracy of dynamic susceptibility-weighted contrast-enhanced perfusion MR imaging in posttreatment gliomas. AJNR Am J Neuroradiol. 2010;31:40-8.

82. Palumbo B, Lupattelli M, Pelliccioli GP, Chiarini P, Moschini TO, Palumbo I, Siepi D, Buoncristiani P, Nardi M, Giovenali P, Palumbo R. Association of 99mTC-MIBI brain SPECT and proton magnetic resonance spectroscopy (1H-MRS) to assess glioma recurrence after radiotherapy. Q J Nucl Med Mol Imaging. 2006;50:88-93.

83. Sundgren PC, Fan X, Weybright P, Elsh RC, Carlos RC, Petrou M, McKeever PE, Chenevert TL. Differentiation of recurrent brain tumor versus radiation injury using diffusion tensor imaging in patients with new contrast-enhancing lesions. Magn Reson Imaging. 2006;24:1131-42.

84. Zeng QS, Li CF, Zhang K, Liu H, Kang XS, Zhen JH. Multivoxel 3D proton MR spectroscopy in the distinction of recurrent glioma from radiation injury. J Neurooncol. 2007;84:63-9.

85. Brandes A, Tosoni A, Spagnolli F, Frezza G, Leonardi M, Calbucci F, Franceschi E. Disease progression or pseudoprogression after concomitant radiochemotherapy treatment: pitfalls in neurooncology. Neuro Oncol. 2008;10:361-7.

86. Hoffman WF, Levin VA, Wilson CB. Evaluation of malignant glioma patients during the postirradiation period. J Neurosurg. 1979;50:624-8.

87. Tofilon PJ, Fike JR. The radioresponse of the central nervous system: a dynamic process. Radiat Res. 2000;153:357-70.

88. DeAngelis L, Delattre J, Posner J. Radiation-induced dementia in patients cured of brain metastases. Neurology. 1989;39:789-96.

89. Nordal R. Hypoxia and hypoxia-inducible factor- 1 target genes in central nervous system radiation injury: a role for vascular endothelial growth factor. Clin Cancer Res. 2004;10:3342-53.

90. Wick W, Wick A, Weiler M, Weller M. Patterns of progression in malignant glioma following anti-VEGF therapy: perceptions and evidence. Curr Neurol Neurosci Rep. 2011;11:305-12. 